\title{
Adiponectin, vitamin D and nutritional status in patients with advanced colorectal cancer or during follow-up
}

\author{
Mariana Abe Vicente CAVAGNARI, Verônica Marques VIDIGAL, Tiago Donizetti SILVA, \\ Katia BARÃO and Nora Manoukian FORONES
}

Received 25/2/2019 Accepted 11/6/2019

\begin{abstract}
Background - Considering the high incidence of colorectal cancer (CRC) related deaths, many studies have investigated variables that can affect survival, with the aim of prolonging survival. The nutritional status can also be predict survival in patients with CRC. Objective - The aim of the present study was to evaluate if BMI, \%FAT, PhA, PG-SGA, adiponectin levels, and vitamin D levels are relevant to the characterization and differentiation of patients with advanced CRC and patients with a history of CRC. Methods - The study was carried out by patients with advanced colorectal cancer (Group 1) and patients in follow-up after colorectal cancer treatment (Group 2). Nutritional status was assessed using the body mass index, body fat percentage, phase angle from bioelectrical impedance, Patient-Generated Subjective Global Assessment score. Adiponectin concentrations were determined using an enzyme-linked immunosorbent assay, and vitamin D levels were measured using high performance liquid chromatography. Results - Groups 1 and 2 consisted of 23 and 27 patients, respectively. The body mass index, body fat percentage, phase angle, vitamin $\mathrm{D}$ and adiponectin levels were not significantly different between the groups. The mean Patient-Generated Subjective Global Assessment score was significantly higher in group 1 compared with group 2, and was significantly correlated with the long-term mortality risk. Conclusion - Among the nutritional status parameters, only the Patient-Generated Subjective Global Assessment score was significantly different between the groups and was an important predictor of survival in patients with advanced colorectal cancer.
\end{abstract}

HEADINGS - Neoplasm metastasis. Colorectal neoplasms. Obesity. Body mass index. Adiponectin. Vitamin D.

\section{INTRODUCTION}

More than 1.2 million new cases of colorectal cancer (CRC) are reported annually, resulting in 600,000 deaths. CRC has become the third most common cancer in the world, making it the fourth leading cause of cancer mortality ${ }^{(1)}$.

Considering the high incidence of CRC-related deaths, a number of studies have investigated factors that affect, or are associated with, mortality, with the aim of prolonging the survival of patients with $\mathrm{CRC}$. The findings of several studies indicate that nutritional status can predict survival in these patients ${ }^{(2-4)}$.

Obesity, which is often assessed using body mass index (BMI) or percentage body fat $(\% \mathrm{FAT})$, is an important nutritional status factor associated with survival in $\mathrm{CRC}^{(4)}$. Baade et al. ${ }^{(5)}$ and Kuiper et al. ${ }^{(6)}$ reported that overweight patients with $\mathrm{CRC}$ had $25 \%$ and $55 \%$ increased CRC-specific mortality rates, respectively. Conversely, other studies have reported no difference in the risk of mortality between overweight and normal weight patients with $\mathrm{CRC}^{(7,8)}$.

Bioelectrical impedance analysis (BIA) provides early predictions of nutritional status by calculating the change in the cell membrane and fluid imbalances. The phase angle (PhA), which is one component of the BIA, determines cellular health and nutritional status by calculating the resistance of body fluid and reactance of the cellular membrane. A high $\mathrm{PhA}$ score indicates a good cellular membrane function, while a low $\mathrm{PhA}$ is closely associated with cell apoptosis and decreased extracellular matrix compounds ${ }^{(9)}$. In previous studies using BIA, the prognostic value of $\mathrm{PhA}$ was demonstrated in pancreatic cancer, lung cancer, breast cancer, and $\mathrm{CRC}^{(10-12)}$. In addition, a $\mathrm{PhA}$ of $<50 \%$ of the standard $\mathrm{PhA}$ was associated with a decreased physical function and nutritional status, and an increased mortality rate in a previous study ${ }^{(13)}$.

The Patient-Generated Subjective Global Assessment (PGSGA) ${ }^{(14)}$, recommended by the Oncology Nutrition Dietetic Practice Group of the American Academy of Nutrition and Dietetics ${ }^{(15)}$, is a standard nutritional assessment tool for cancer patients. It emphasizes symptoms commonly observed during the treatment of cancer and includes a physical examination for the subjective assessment of nutritional status. The PG-SGA is an important tool that predicts survival ${ }^{(16)}$, and patient-reported outcomes are particularly important for survival prediction ${ }^{(17)}$.

Adiponectin is a $30-\mathrm{kDa}$ protein hormone and cytokine that is secreted mainly by adipocytes, is structurally related to the collagen superfamily, and shares homologies with collagens, complement factors, and tumor necrosis factor- $\alpha^{(18)}$. It is the most abundant hormone secreted by adipose tissue and circulates as low molecular weight and high molecular weight multimers ${ }^{(18)}$. Epidemiological studies have suggested that circulating adiponectin levels are inversely correlated with the risk of obesity-associated CRC, and

Declared conflict of interest of all authors: none

Disclosure of funding: this study was supported by the São Paulo Research Foundation (FAPESP, grant 10/19191-2)

Universidade Federal de São Paulo (UNIFESP), Setor de Oncologia, Disciplina de Gastroenterologia Clínica, Departamento de Medicina, São Paulo, SP, Brasil.

Corresponding author: Mariana Abe Vicente Cavagnari. E-mail: marianaav@hotmail.com 
accumulating evidence supports an inverse relationship between circulating adiponectin levels and obesity, suggesting that adiponectin may mediate the biological link between obesity and $\mathrm{CRC}^{(19-21)}$. In addition, higher levels of adiponectin receptor expression are observed in CRC than in normal tissues, further supporting this hypothesis ${ }^{(21)}$. However, there is a paucity of data on the effect of adiponectin on survival among patients with established CRC.

The vitamin $\mathrm{D}$ hypothesis has received strong experimental support over the past two decades, based on the almost ubiquitous expression in colon cancer cells of vitamin D receptors (VDR) 1,2 and hydroxylase,3, which convert plasma 25-hydroxyvitamin D3 [25(OH)D] into 1,25-dihydroxyvitamin D3 [1,25(OH)2D]. Binding of VDR by $1,25(\mathrm{OH}) 2 \mathrm{D}$ leads to multiple cellular effects, including the induction of differentiation and apoptosis ${ }^{(22)}$, and inhibition of proliferation, angiogenesis ${ }^{(23)}$, and metastatic potential ${ }^{(24)}$.

Prospective studies have demonstrated that higher baseline plasma $25(\mathrm{OH}) \mathrm{D}$ levels are associated with a significantly reduced risk of $\mathrm{CRC}^{(25-26)}$. Emerging evidence in the literature suggests an association between serum $25(\mathrm{OH}) \mathrm{D}$ levels and survival in $\mathrm{CRC}^{(27,28)}$, however, the relationship between vitamin D and CRC-related mortality is not well understood ${ }^{(29)}$.

Although the BMI, \%FAT, PhA, PG-SGA score, and adiponectin and vitamin $\mathrm{D}$ levels have been correlated with survival in patients with CRC, their prognostic utility in patients with advanced cancer is not clear.

The aim of the present study was to evaluate whether the BMI, $\%$ FAT, PhA, PG-SGA score, and adiponectin and vitamin D levels are relevant for the characterization and differentiation of patients with advanced CRC compared with patients in follow-up following treatment for CRC. In addition, we aimed to determine whether these variables are important for the survival of patients with CRC.

\section{METHODS}

\section{Subjects}

This longitudinal study involved outpatients treated between February 2011 and March 2012 by the Oncology Group from the Gastroenterology Division of the Federal University of Sao Paulo, Brazil. The patients were evaluated in a single moment and the survival was evaluated until the year 2016. The study was approved by the local Ethics Committee (Protocol 0826/10 and 0029/11), and all patients signed an informed consent form. There were two groups of patients: group 1, which included patients with metastatic CRC undergoing chemotherapy; and group 2, which included patients in follow-up following treatment for CRC and who had been tumor free for $>6$ months.

\section{Data collection}

The sex, age, treatment, site, death, and tumor stage data were obtained from the patient medical records. The nutritional evaluation and blood sample collection to measure serum adiponectin and vitamin D levels were performed simultaneously. All patients were classified according to the tumor-node-metastasis staging system $^{(30)}$. The BMI was calculated as weight $(\mathrm{kg})$ divided by height $\left(\mathrm{m}^{2}\right)$, and classified according to the World Health Organization criteria ${ }^{(31)}$. The PhA and \%FAT were determined using the Biodynamics $450^{\circledR}$ analyzer and a standard protocol. PhA was calculated as the ratio between resistance $(\mathrm{R})$ and reactance $(\mathrm{Xc})$; $\mathrm{R}$ and $\mathrm{Xc}$ were measured directly in ohms at a single frequency of $50 \mathrm{kHz}$ and $800 \mu \mathrm{A}$. All procedures and controls for other variables affecting the validity, reproducibility, and precision of the measurements were performed according to the National Institutes of Health guidelines ${ }^{(32)}$. The $\%$ FAT was classified according to the criteria by Gallagher et al. ${ }^{(33)}$.

The validated Portuguese version of the scored PG-SGA was used to assess nutritional status, which was classified as the following $^{(34)}$ : (A) well-nourished, (B) moderately undernourished or suspected of being undernourished, and (C) severely undernourished.

\section{Adiponectin assay}

Blood samples were collected in the morning after overnight fasting. The serum samples were clotted and centrifuged at $2000 \times \mathrm{g}$ for $10 \mathrm{~min}$ and immediately frozen at $-80^{\circ} \mathrm{C}$ for further analysis. Adipocytokine levels were measured using an enzyme-linked immunosorbent assay (ELISA) kit (R\&D Systems, MN, USA), and adiponectin levels (with the sample diluted 4,000-fold) were measured using the DuoSet ${ }^{\circledR}$ ELISA kit (DY1065; R\&D Systems). The analytical methodology and technical procedures were performed according to the manufacturer's protocol.

\section{Vitamin D assay}

Current and active vitamin D concentrations were measured using appropriate high performance liquid chromatography equipment, which was calibrated using a standard curve, analytical standards, and controls. The standard was provided by SigmaAldrich (St. Louis, MO, USA; C9774), the control was provided by Chromsystems (25-OH-Vitamin D3 serum control, Bi-level I + II), and the calibration curves were validated daily, with minor acceptable deviations of 5\%. Measurement of samples was repeated when the values were lower or higher than the reference range (20-120 ng/mL).

The average circulating serum vitamin $\mathrm{D}$ concentration was classified as deficient $(<20 \mathrm{ng} / \mathrm{mL})$, insufficient $(20-29.9 \mathrm{ng} / \mathrm{mL})$, or sufficient $(\geq 30 \mathrm{ng} / \mathrm{mL})$. For the average active vitamin $\mathrm{D}$ concentrations, deficient was defined as $<15 \mathrm{pg} / \mathrm{mL}$, sufficient was defined as $15-78 \mathrm{pg} / \mathrm{mL}$, and high was defined as $>78 \mathrm{pg} / \mathrm{mL}$.

\section{Statistical analysis}

Data are presented as percentages or the mean \pm standard deviation. Differences between variables presented as percentages were assessed using chi-square tests. The normality of the results was tested using the Shapiro-Wilk test. The normally distributed continuous variables were assessed using Student's independent $t$-tests and variables that non-parametric used Wilcoxon test.

To evaluate adiponectin levels and the PhA, a cutoff value was established for the population studied due to the lack of specific values for cancer patients. The values were divided by the distribution of the proportion of observed frequencies for both groups. The data were separated into quartiles, and the first quartile was defined as predictors of low levels and undernutrition for adiponectin and $\mathrm{PhA}$, respectively. Survival analysis was conducted using the Kaplan-Meier method and evaluated using the log rank test. The SPSS 20.0 software (IBM Corp., Armonk, NY, USA) was used for statistical analyses. $p<0.05$ was considered statistically significant.

\section{RESULTS}

Among the 50 patients who were eligible for the study, 23 were in group 1 and 27 were in group 2. Sex and age were not signifi- 
cantly different between the groups. The majority of group 2 had stage II tumors $(51.8 \%)$. In both groups, the samples were collected predominantly during the winter. According PG-SGA, 47,8\% and $25,9 \%$ patients were moderately undernourished, respectively in group 1 and 2 (TABLE 1).

The BMI, \%FAT, PhA, and 25(OH)D, 1,25(OH)D, and adiponectin levels were not significantly different between the groups, although the values were generally lower in group 1 . The mean PG-SGA score was higher in group 1, median 8 points compared with group 2 , median 2 points $(P=0.002)$ (TABLE 2$)$.

In the crude Kaplan-Meier analysis, the BMI, $\%$ FAT, PhA, and $25(\mathrm{OH}) \mathrm{D}, 1,25(\mathrm{OH}) \mathrm{D}$, and adiponectin levels were not correlated with the long-term $\mathrm{CRC}$-specific mortality risk. Only the PG-SGA score was significantly ( $\log \operatorname{rank} P=0.031)$ correlated with the longterm mortality risk (FIGURE 1).

\section{DISCUSSION}

In the present study, the majority of the parameters of nutritional status (BMI, \%FAT, PhA, and serum adiponectin and vitamin $\mathrm{D}$ levels) did not differ significantly between patients with advanced CRC and those with previous CRC. However, the PG-SGA score differed significantly between the two groups of patients, and was significantly higher among the patients with advanced disease. The PG-SGA score also served as a prognostic factor; patients with severe malnutrition had lower survival rates.

An association between PG-SGA scores and mortality has been reported previously ${ }^{(16)}$, and patient-reported outcomes were shown to be important for predicting survival ${ }^{(17)}$. One hypothesis for the PG-SGA score representing the only difference between these groups was that it was the only parameter that was not directly influenced by obesity. Even overweight patients can have a high PG-SGA score as a result of weight loss, symptoms that interfere with food intake, changes in functional capacity, and the physical examination.

In the present study, PhA values were lower in the patients with advanced CRC than in the patients with a history of $\mathrm{CRC}$, as described in previous studies ${ }^{(12,13)}$. However, a significant difference between the groups was not observed in this study. Those patients with a $\mathrm{PhA}$ value below the first quartile have a worse prognosis. One limitation of the interpretation of the $\mathrm{PhA}$ value as a prognostic index may be related to not only the analysis approach, but also the period.

The lack of significant differences in the BMI, \%FAT, PhA, and adiponectin and vitamin $\mathrm{D}$ levels between the two groups in the present study may have been due to the similar percentages of overweight or obese patients in the two groups (approximately 40\%). In the present study, an association between obesity and disease progression in CRC was not observed. Previous studies have demonstrated that being underweight is associated with an increased risk of death due to cancer progression-associated weight loss ${ }^{(7,8)}$.

Obesity, as indicated by the BMI and \%FAT, might justify the low serum adiponectin and vitamin D levels. High BMI and \%FAT are reportedly risk factors for $\mathrm{CRC}^{(4-6)}$; this is supported by the similarities in the variables between the groups in the present study. Regarding the risk of disease recurrence, a consensus regarding the association between insufficient serum vitamin D levels and an increased risk of recurrence has not been reached, although there is a tendency to replenish vitamin D in patients with CRC and low vitamin $\mathrm{D}$ levels.

TABLE 1. Baseline characteristics of colorectal cancer patients (Group 1) and controls (Group 2).

\begin{tabular}{lccc}
\hline Parameters & Group 1 & Group 2 & $\boldsymbol{P}$-value \\
\hline Age (years) & $58.2 \pm 10.2$ & $59.6 \pm 11.9$ & 0.630 \\
Sex & & & \\
$\quad$ Male & $12(52.2)$ & $15(55.6)$ & 0.855 \\
Female & $11(47.8)$ & $12(44.4)$ &
\end{tabular}

Stage
I
II
III
IV

\section{Rated season}

Summer

Autumn

Winter

Spring

\section{BMI}

$<18.5$ (undernourished)

18.5-24.9 (normal)

25-29.9 (overweight)

$\geq 30.0$ (obese)
$\%$ Fat mass

\section{Adequate}
High fat mass

PhA

$$
>\text { First quartile }
$$

$\leq$ First quartile

\section{PG-SGA}

Severely undernourished

Moderately undernourished

Well nourished

\section{Adiponectin

$$
>\text { First quartile }
$$ \\ $\leq$ First quartile}

\section{1,25 (OH) D}

\section{Deficient / insufficient}

Sufficient

$25(\mathrm{OH}) \mathrm{D}$

Deficient / insufficient

Sufficient

$11(47.9)$

$12(48)$

$<0.001$

0.256

8 (29.6)

$11(40.7)$

$16(59.2)$

0.630

Data are presented as the mean \pm standard deviation or $\mathrm{n}(\%)$. BMI, body mass index. 
TABLE 2. Mean, median, minimum and maximum values of BMI, \% Fat mass, phase angle, Score PG-SGA, adiponectin, 1,25 (OH) D and $25(\mathrm{OH}) \mathrm{D}$.

\begin{tabular}{|c|c|c|c|}
\hline Variables & Mean \pm SD & Median $^{\dagger}$ & $P$-value \\
\hline \multicolumn{4}{|l|}{ BMI $\left(\mathrm{kg} / \mathrm{m}^{2}\right)$} \\
\hline G1 & $24.5 \pm 3.5$ & $24.7(18.5-31.3)$ & \multirow{2}{*}{$0.129 *$} \\
\hline G2 & $26.3 \pm 4.3$ & $26.2(17.8-39.1)$ & \\
\hline \multicolumn{4}{|l|}{$\%$ Fat mass } \\
\hline G1 & $25.1 \pm 8.1$ & $26.9(6.5-41.9)$ & \multirow{2}{*}{$0.500 *$} \\
\hline G2 & $26.7 \pm 8.4$ & $28.9(12-43.0)$ & \\
\hline \multicolumn{4}{|l|}{$\mathrm{PhA}$} \\
\hline G1 & $5.8 \pm 1.1$ & $5.7(3.8-8.0)$ & \multirow{2}{*}{$0.101 *$} \\
\hline G2 & $6.3 \pm 1.0$ & $6.4(4.3-8.5)$ & \\
\hline \multicolumn{4}{|l|}{ Score PG-SGA } \\
\hline G1 & $9.7 \pm 7$ & $9(1-25)$ & \multirow{2}{*}{$0.002 *$} \\
\hline G2 & $4 \pm 4.8$ & $2(0-16)$ & \\
\hline \multicolumn{4}{|c|}{ Adiponectin $(\mu \mathrm{g} / \mathrm{mL})$} \\
\hline G1 & $12.5 \pm 2.7$ & $12.8 \pm(5-15)$ & \multirow{2}{*}{$0.066 * *$} \\
\hline G2 & $10.4 \pm 3.4$ & $12.18(2.5-14.2)$ & \\
\hline \multicolumn{4}{|c|}{$1.25(\mathrm{OH}) \mathrm{D}(\mathrm{ng} / \mathrm{mL})$} \\
\hline G1 & $28.3 \pm 18.6$ & $20.6(11.5-87.9)$ & \multirow{2}{*}{$0.796 * *$} \\
\hline G2 & $29.5 \pm 14$ & $26.8(11.8-66.9)$ & \\
\hline \multicolumn{4}{|c|}{$25(\mathrm{OH}) \mathrm{D}(\mathrm{pg} / \mathrm{mL})$} \\
\hline G1 & $28.8 \pm 16.3$ & $28(6.3-68.7)$ & \multirow{2}{*}{$0.585^{*}$} \\
\hline G2 & $31.6 \pm 19.1$ & $27.3(7-86)$ & \\
\hline
\end{tabular}

Group 1: G1, Group 2: G2; *t-tests; **Wilcoxon test. ${ }^{\dagger}$ minimum-maximum.
Serum adiponectin levels are associated with obesity, the risk of CRC, and a poor prognosis ${ }^{(20)}$. In the present study, the serum adiponectin levels did not differ significantly between the two groups, and there was no correlation between the different adiponectin quartiles and survival; however, patients with adiponectin levels in the first quartile had lower median survival rates.

To date, studies have shown that the pleiotropic roles of adiponectin in carcinogenesis are complex and controversial ${ }^{(20)}$. Anti-carcinogenic properties for adiponectin have been attributed to the activation of the adenosine monophosphate-activated protein kinase (AMPK) pathway, leading to apoptosis and inhibition of proliferation ${ }^{(18)}$; direct inhibition of the phosphoinositide 3-kinase/protein kinase-B pathway, which is responsible for cell survival; and modulation of insulin sensitization and inflammation $^{(18,20,21)}$. Conversely, adiponectin was shown to promote oncogenesis through stimulation of pro-inflammatory cytokines, such as interleukin-8, inhibition of apoptosis via activation of AMPK/Sirtuin 1/peroxisome proliferator-activated receptor gamma coactivator 1 alpha ${ }^{(18)}$ and promotion of angiogenesis, and colonic proliferation ${ }^{(18,20,21)}$.

Since adiponectin regulates signaling pathways that consequently affect serum levels, the similarity in adiposity between the groups was more striking than the presence of a tumor in the present study. However, the evidence relating to adiponectin in the present study might be limited by the small sample size, single dose, and analysis of the total adiponectin level, rather than high molecular weight adiponectin.

A better understanding of the relationship between the analyzed variables and CRC is required. In addition, monitoring of these variables is needed to assist clinicians with possible interventions and to estimate survival with improved accuracy. Despite the importance of this study, some limitations were present, including the sample size and that approximately $40 \%$ of the patients were overweight; therefore, sufficient power might

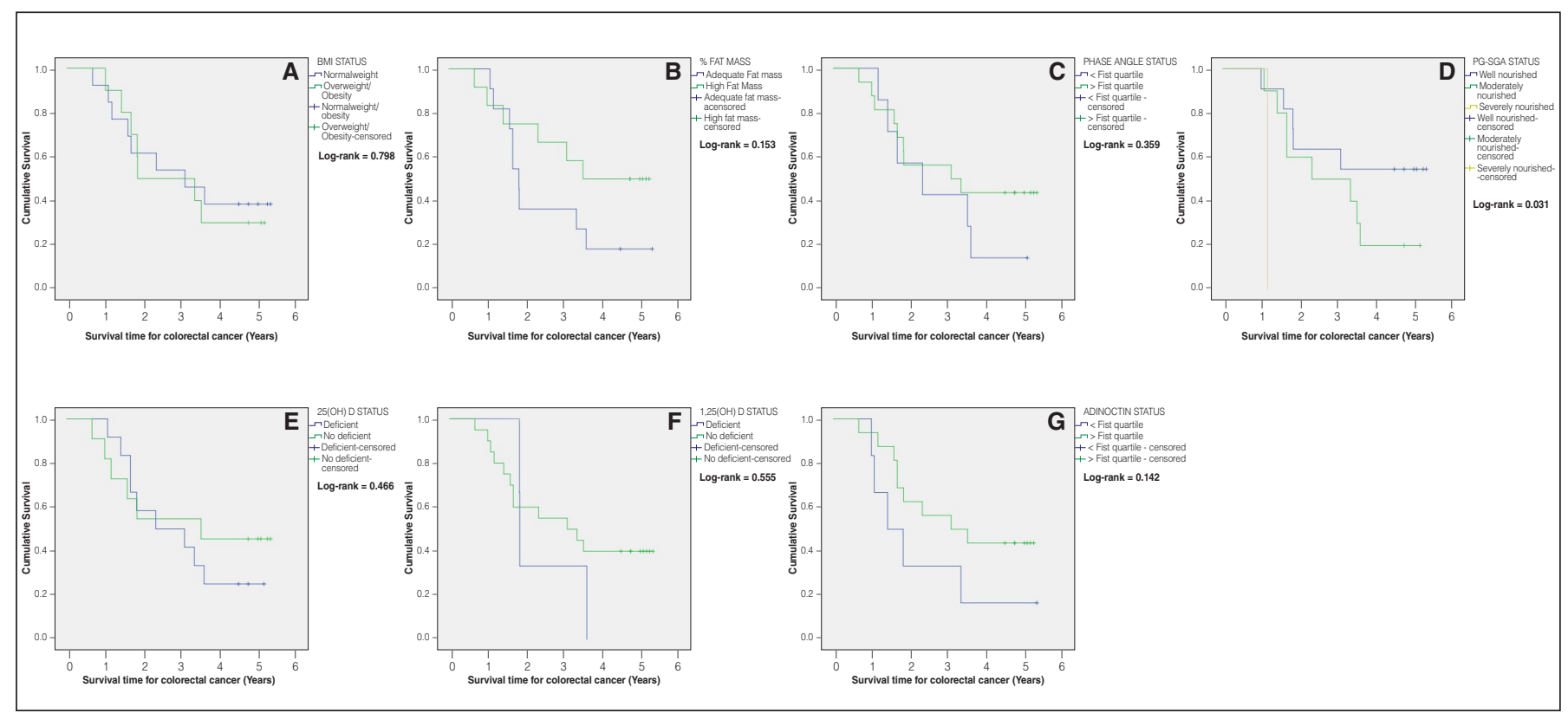

FIGURE 1. Colorectal cancer survival according to the BMI (A), \%FAT (B), phase angle (C), PG-SGA score (D), and 25(OH)D (E), 1,25(OH)D (F), and adiponectin levels (G) of patients. BMI, body mass index; \%FAT, body fat percentage; PG-SGA, Patient-Generated Subjective Global Assessment; 25(OH)D, 25-hydroxyvitamin D; 1,25(OH)D, 1,25-hydroxyvitamin D. 
not have been present to demonstrate differences in the variables Furthermore, the cross-sectional design did not allow for evaluation of longitudinal changes.

PG-SGA is a tool considered important for nutritional diagnosis and also for patient survival. However, depending on the moment the patient is evaluated, PG-SGA will not be effective to correlate with survival ${ }^{(17,35)}$. It is observed that changes in body composition $^{(36)}$, such as body fat in FIGURE 1B, can be related to the survival of the patient with CRC.

The comparisons of nutritional status parameters between the patients with advanced CRC and those who were undergoing follow-up showed no significant differences in the BMI, PhA, $\%$ FAT, and serum adiponectin and vitamin D levels between the two groups. The PG-SGA score was significantly different between the two groups and was an important predictive parameter for survival in patients with advanced CRC. We recommend that additional studies involving longitudinal monitoring of nutritional parameters be performed, in order to determine the sensitivity to changes at different time periods and to predict survival. This should allow the best treatment plan to be determined based on the nutritional status of a patient.

\section{ACKNOWLEDGEMENTS}

The authors gratefully acknowledge the Fundação de Amparo à Pesquisa do Estado de São Paulo for providing financial support (10/19191-2).

\section{Authors' contribution}

Cavagnari MAV and Forones NM equally contributed to the conception and design of the research; Cavagnari MAV, Vidigal VM, Silva TD and Barão K contributed to the acquisition and analysis of the data; Cavagnari MAV and Forones NM contributed to the interpretation of the data; and Cavagnari MAV and Forones $\mathrm{NM}$ drafted the manuscript. All authors critically revised the manuscript, agree to be fully accountable for ensuring the integrity and accuracy of the work, and read and approved the final manuscript.

\section{Orcid}

Mariana Abe Vicente Cavagnari. Orcid: 0000-0003-4352-4659.

Verônica Marques Vidigal. Orcid: 0000-0002-4062-0015.

Tiago Donizetti Silva. Orcid: 0000-0002-0274-3604.

Katia Barão. Orcid: 0000-0001-9975-4109.

Nora Manoukian Forones. Orcid: 0000-0001-9414-0343.

Cavagnari MAV, Vidigal VM, Silva TD, Barão K, Forones NM. Adiponectina, vitamina D e estado nutricional em pacientes com câncer colorretal avançado e em seguimento. Arq Gastroenterol. 2019;56(2):172-7.

RESUMO - Contexto - Considerando a alta incidência de óbitos devido ao câncer coloretal (CCR), estudos investigaram variáveis que podem afetar a sobrevida, com objetivo de prolongar a sobrevida. O estado nutricional desses pacientes também pode predizer a sobrevida. Objetivo - O objetivo do presente estudo foi avaliar se o índice de massa corporal (IMC), a porcentagem de gordura, os níveis séricos de adiponectina e de vitamina D são relevantes para a caracterização e diferenciação de pacientes com CCR avançado e pacientes com histórico de CCR. Métodos - O estudo foi realizado por pacientes com câncer colorretal avançado (Grupo 1) e pacientes em acompanhamento após o tratamento do CCR (Grupo 2). O estado nutricional foi avaliado por meio do IMC, percentual de gordura corporal, ângulo de fase da bioimpedância elétrica, escore de Avaliação Global Subjetiva Gerada pelo Paciente. As concentrações de adiponectina foram determinadas por ELISA e os níveis de vitamina D foram medidos por meio de cromatografia líquida de alta performance. Resultados - Os grupos 1 e 2 consistiram de 23 e 27 pacientes, respectivamente. O IMC, percentual de gordura corporal, ângulo de fase, níveis de vitamina D e adiponectina não foram significativamente diferentes entre os grupos. O escore médio da Avaliação Global Subjetiva Gerada pelo Paciente foi significativamente maior no grupo 1 em comparação com o Grupo 2, e foi significativamente correlacionado com o risco de mortalidade a longo prazo. Conclusão - Entre os indicadores do estado nutricional, apenas o escore da Avaliação Global Subjetiva Gerada pelo Paciente foi significativamente diferente entre os grupos e foi um importante preditor de sobrevida em pacientes com câncer colorretal avançado. DESCRITORES - Metástase neoplásica. Neoplasias colorretais. Obesidade. Índice de massa corporal. Adiponectina. Vitamina D

\section{REFERENCES}

1. Bray F, Ferlay J, Soerjomataram I, Siegel RL, Torre LA, Jemal A. Global cancer statistics 2018: GLOBOCAN estimates of incidence and mortality worldwide for 36 cancers in 185 countries. CA Cancer J Clin. 2018; 68:394-424.

2. Nishiyama VKG, Albertini SM, Moraes CMZG, Godoy MF, Netinho JG. Malnutrition and clinical outcomes in surgical patients with colorectal disease. Arq Gastroenterol. 2018;55:397-402

3. Ou B, Zhao J, Guan S, Lu A. Plasma 25-hydroxyvitamin D levels and survival of colorectal cancer patients: a meta-analysis. Eur J Cancer. 2015;51:786-8.

4. Lee J, Meyerhardt JA, Giovannucci E, Jeon JY. Association between body mass index and prognosis of colorectal cancer: a meta-analysis of prospective cohort studies. PLoS One. 2015;10:1-25.

5. Baade PD, Meng X, Youl PH, Aitken JF, Dunn J, Chambers SK. The impact of body mass index and physical activity on mortality among patients with colorectalcancer in Queensland, Australia. Cancer Epidemiol Biomarkers Prev. 2011;20:1410-20

6. Kuiper JG, Phipps AI, Neuhouser ML, Chlebowski RT, Thomson CA, Irwin ML, et al. Recreational physical activity, body mass index, and survival in women with colorectal cancer. Cancer Causes Control. 2012;23:1939-48.
7. Meyerhardt JA, Tepper JE, Niedzwiecki D, Hollis DR, McCollum AD, Brady D, et al. Impact of body mass index on outcomes and treatment-related toxicity in patients with stage II and III rectal cancer: findings from Intergroup Trial 0114. J Clin Oncol. 2004;22:648-57.

8. Dignam JJ, Polite BN, Yothers G, Raich P, Colangelo L, O'Connell MJ, Wolmark $\mathrm{N}$. Body mass index and outcomes in patients who receive adjuvant chemotherapy for colon cancer. J Natl Cancer Inst. 2006;98:1647-54

9. Kyle UG, Bosaeus I, De Lorenzo AD, Deurenberg P, Elia M, Gómez JM, et al. Bioelectrical impedance analysis - part I: review of principles and methods. Clin Nutr. 2004;23:1226-43.

10. Paiva SI, Borges LR, Halpern-Silveira D, Assunção MC, Barros AJ, Gonzalez MC. Standardized phase angle from bioelectrical impedance analysis as prognostic factor for survival in patients with cancer. Support Care Cancer 2010;19:187-92.

11. Gupta D, Lammersfeld CA, Burrows JL, Dahlk SL, Vashi PG, Grutsch JF, et al. Bioelectrical impedance phase angle in clinical practice: implications for prognosis in advancedcolorectal cancer. Am J Clin Nutr. 2004;80:1634-8.

12. Hui D, Bansal S, Morgado M, Dev R, Chisholm G, Bruera E. Phase Angle for Prognostication of Survival in Patients with Advanced Cancer: Preliminary Findings. Cancer. 2014;120:2207-14. 
13. Norman K, Stobäus N, Zocher D, Bosy-Westphal A, Szramek A, Scheufele R, Bruera E. Cutoff percentiles of bioelectrical phase angle predict functionality, quality of life, and mortality in patients with cancer. Am J Clin Nutr. 2010;92: 612-9.

14. Ottery FD. Definition of standardized nutritional assessment and interventional pathways in oncology. Nutrition 1996; 12:15-19.

15. McCallum PD, Polisena C (eds): Patient-generated subjective global assessment, The Clinical Guide to Oncology Nutrition. The American Dietetic Association 2000. 11-23.

16. Martin L, Watanabe S, Fainsinger R, Lau F, Ghosh S, Quan H, Atkins M, Fassbender K, Downing GM, Baracos V. Prognostic factors in patients with advanced cancer: use of the patient-generated subjective global assessment in survival prediction. J Clin Oncol. 2010; 28:4376-83.

17. Gotay CC, Kawamoto CT, Bottomley A, Efficace F. The prognostic significance of patient-reported outcomes in cancer clinical trials. J Clin Oncol. 2008;26:1355-63.

18. Simpson F, Whitehead JP. Adiponectin--it's all about the modifications. Int J Biochem Cell Biol. 2010;42:785-8.

19. Pais R, Silaghi H, Silaghi AC, Rusu ML, Dumitrascu DL. Metabolic syndrome and risk of subsequent colorectal cancer. World J Gastroenterol. 2009; 15:5141-8.

20. Arita Y, Kihara S, Ouchi N, Takahashi M, Maeda K, Miyagawa J, et al. Paradoxical decrease of an adipose-specific protein, adiponectin, in obesity. Biochem Biophys Res Commun. 1999; 257:79-83.

21. Williams CJ, Mitsiades N, Sozopoulos E, Hsi A, Wolk A, Nifli AP, Tseleni-Balafouta S, Mantzoros CS. Adiponectin receptor expression is elevated in colorectal carcinomas but not in gastrointestinal stromal tumors. Endocr Relat Cancer. 2008;15:289-99.

22. Vandewalle B, Wattez N, Lefebvre J. Effects of vitamin D3 derivatives on growth, differentiation and apoptosis in tumoral colonic HT 29 cells: Possible implication of intracellular calcium. Cancer Lett. 1995;97:99-106.

23. Iseki K, Tatsuta M, Uehara H, Iishi H, Yano H, Sakai N, Ishiguro S. Inhibition of angiogenesis as a mechanism for inhibition by lalphahydroxyvitamin D3 and 1,25-dihydroxyvitamin D3 of colon carcinogenesis induced by azoxymethane in Wistar rats. Int J Cancer. 1999 81:730-3

24. Fernandez-Garcia NI, Palmer HG, Garcia M, Gonzalez-Martin A, del Rio M, Barettino D, Volpert O, Muñoz A, Jimenez B. 1alpha,25-Dihydroxyvitamin D3 regulates the expression of Id 1 and Id 2 genes and the angiogenic phenotype of human colon carcinoma cells. Oncogene. 2005;24:6533-44.
25. Elizabeth T. Jacobs, Lindsay N. Kohler, Andrew G. Kunihiro, Peter W. Jurutka. Review Vitamin D and Colorectal, Breast, and Prostate Cancers: A Review of the Epidemiological Evidence. J Cancer. 2016; 7: 232-240.

26. Choi YJ, Kim YH, Cho CH, Kim SH, Lee JE. Circulating levels of vitamin D and colorectal adenoma: A case-control study and a meta-analysis. World $\mathbf{J}$ Gastroenterol. 2015;21:8868-77.

27. Mohr SB, Gorham ED, Kim J, Hofflich H, Cuomo RE, Garland CF. Could vitamin D sufficiency improve the survival of colorectal cancer patients? J Steroid Biochem Mol Biol. 2015;148:239-44.

28. Toriola AT, Nguyen N, Scheitler-Ring K, Colditz GA. Circulating 25-hydroxyvitamin D levels and prognosis among cancer patients: a systematic review. Cancer Epidemiol Biomarkers Prev. 2014;23:917-33.

29. Ashmore JH, Gallagher CJ, Lesko SM, Muscat JE, Hartman TJ, Lazarus P. No association between vitamin $\mathrm{D}$ intake, VDR polymorphisms, and colorectal cancer in a population-based case-control study. Cancer Epidemiol Biomarkers Prev. 2015;24:1635-7.

30. Sobin LH, Gospodarowicz MK, Wittekind Ch (eds): TNM Classification of Malignant Tumours (ed 7). West Sussex, United Kingdom, Wiley-Blackwell, 2009.

31. Organización Mundial de la Salud. El estado físico: uso e interpretación de la antropometría. Genebra: OMS; 1995. p. 452.

32. [No authors listed]. NIH Consensus statement. Bioelectrical impedance analysis in body composition measurement. National Institutes of Health Technology Assessment Conference Statement. December 12-14, 1994. Nutrition 1996; 12: 749-62.

33. Gallagher D, Heymsfield SB, Heo M, Jebb SA, Murgatroyd PR, Sakamoto Y. Healthy percentage body fat ranges: an approach for developing guidelines based on body mass index. Am J Clin Nutr. 2000;72:694-701.

34. Gonzalez MC, Borges LR, Silveira DH, Assunção MCF, Orlandi SP. Validação da versão em português da avaliação subjetiva global produzida pelo paciente. Rev Bras Nutr Clin 2010; 25: 102-8.

35. Ræder H, Henriksen C, Bøhn SK, O de Fey Vilbo AR, Henriksen HB, Kværner AS. Agreement between PG-SGA category and fat-free mass in colorectal cancer patients. Clin Nutr ESPEN. 2018; 27:24-31

36. Charette N, Vandeputte C, Ameye L, Bogaert CV, Krygier J, Guiot T Prognostic value of adipose tissue and muscle mass in advanced colorectal cancer: a post hoc analysis of two non-randomized phase II trials. BMC Cancer. 2019; 12;19:134. 